\title{
ANALYSIS OF BREAST PAIN: A STUDY OF 110 CASES
}

\author{
RIAZ AHMED CHOWDHURY1 ${ }^{1}$,SYED KHALID HASAN ${ }^{2}$, JAFAR MD MASUD ${ }^{3}$
}

\begin{abstract}
:
A prospective type of analytical study was carried out on 106 patients with breast pain to analyze the causes of breast pain. This study was conducted from August, 2002 to January 2004 at breast clinic of Bangladesh Medical College Hospital (BMCH) and at Department of Surgery of BMCH. Sampling was done purposively and a structured questionnaire was used for data collection by interviewing followed by examining the patient in the first phase. In the second phase, Mammography and FNAC (Fine Needle Aspiration Cytology) was done. Majority of the patients (35.8\%) were in the age group of 21-30 years and the mean age was $27.61 \pm$ SD10.5 years. About $48.1 \%$ breast pains were due to ANDI (Aberration of Normal Development and Involution) and among the other causes nonspecific pain $15.1 \%$, breast abscess $14.2 \%$ and carcinoma of breast were only $1.9 \%$. The performance status of all the patients were in between 0 - 1. Mammography was done in 54 patients and of them 44 was found positive for fibrocystic disease (41 cases) and fibroadenoma (3 cases). FNAC was done in 50 patients and 36 were found positive with fibroadenoma (22 cases), fibrocystic change (8 cases), chronic breast abscess (2 cases), mitotic lesion (2 cases), and neurofibroma (2 cases). So painful breast diseases are helpful in seeking further medical care for appropriate intervention
\end{abstract}

Keyword: Breast pain, Mastalgia, ANDI.

\section{Introduction:}

Patients with breast-problems make up a major part of the patient load at a general surgical out-patients' clinics. Majority of patients correlates breast pain with breast cancer. Virtually, every women with a breast lump, breast pain or discharge from nipple fears that she has breast-cancer. The anxiety that result is made of three components: the unknown course of the diseases, the threat of mutilation and the fear of death; all these, compounded by social and cultural norms among certain groups, often prevented women from seeking early medical advice. In recent years, specially in the west, public awareness and media publicity about self-examination and screening and the possible advantages of early treatment have encouraged earlier presentation, which of course is not without its disadvantages; the psychological consequences of false - alarms and false-reassurances cannot be ignored all together. Unfortunately, the majority of the sufferers in this part of the world are far from being aware of the disease process and thus present only when it is too late. This is especially applicable in case of breast cancer, "The captain of the breast-disease". It is the common cancer in the women and the most common cause of death in women between $35-55$ years. ${ }^{1}$ The incidence of breast cancer is rising but mortality has not risen, probably as a result of earlier detection and improved treatment. Breast cancer is not, however, a new disease; it was recognized by the ancient Egyptians and mastectomy was certainly performed in Roman times. ${ }^{1}$

The other conditions of the breast are the benign breast disease. A majority of these are coined under ANDI (Aberrations of Normal Development and Involution) by Cardiff Breast Clinic to avoid different terminologies and confusion. ${ }^{2}$

The common benign breast diseases are fibroadenosis and fibroadenoma, both controlled by hormonal factors; fibroadenoma is common in younger women while fibroadenosis between 30 to 40 years. ${ }^{2}$

Breast infections most commonly occur during pregnancy and lactation. Equally, not uncommon breast condition is Mastalgia or Mastodynia, described first by Sir Astley Cooper. ${ }^{2}$ it may or may not be cyclical and may or may not be associated with

1. Associate Professor, Department of Surgery, Bangladesh Medical College, Dhaka

2. Registrar, Department of Surgery, Bangladesh Medical College, Dhaka

3. Assistant Professor, Department of Oncology, Bangladesh Medical College, Dhaka

Correspondence : Dr. Riaz Ahmed Chowdhury, Associate Professor, Department of Surgery, Bangladesh Medical College, Dhaka 
nodules. Many people still believe that Mastodynia is incompatible with breast cancer but one third of the patients with sub-clinical breast cancer present with pain. ${ }^{1,3}$

It may be mentioned here that proper analysis of breast pain and its appropriate management is associated with sound female health. So keeping this in mind, this study was done to evaluate the causes of breast pain.

\section{Materials and methods:}

This prospective analytical study was done on 106 patients with a complain of breast pain at breast clinic of Bangladesh Medical College Hospital and at Surgical Department of BMCH from August 2002 to January 2004. By purposive sampling a total of 106 patients with breast pain were selected. A structured questionnaire was filled up by interviewing on various socio-demographic variables, by evaluating the performance status and examining the patient in the first phase. In the second phase Mammography and FNAC were done. Data were compiled, edited and presented by frequency distribution table using the software SPSS.

Performance status was evaluated by following UICC (Union against Cancer Commission) performance status:

0 able to carry out normal activity

1 able to live at home, with tolerable symptoms

2 disabling symptoms but less than $50 \%$ of time in bed

3 severely disabled, greater than $50 \%$ of time in bed but able to stand

4 very ill confined to bed

5 death

\section{Results:}

Table-I

Distribution of the age of the respondents $(n=106)$

\begin{tabular}{lcc}
\hline Age Group & Number of patients & Percent \\
\hline$<10$ & 2 & 1.9 \\
$11-20$ & 30 & 28.4 \\
$21-30$ & 38 & 35.8 \\
$31-40$ & 23 & 21.7 \\
$41-50$ & 10 & 9.4 \\
$>50$ & 3 & 2.8 \\
\hline Total & 106 & $100 \%$ \\
\hline
\end{tabular}

The age range of the patients was 10-72 and mean age was $27.61 \pm$ SD- 10.5 years.

Table-I shows the maximum patient in study group were in the age group of 21- 30 years (35.8\%).About $28.4 \%$ and $21.7 \%$ were in the age group of $11-20$ and $31-40$ years respectively. Only $1.9 \%$ (2 in number) was of $<10$ years.

Table-II

Distribution of patients presented with breast pain according to the causes $(n=106)$

\begin{tabular}{lcc}
\hline $\begin{array}{l}\text { Diagnosis of patient } \\
\text { with breast pain }\end{array}$ & No of patients & Percent \\
\hline ANDI & 51 & 48.1 \\
Breast abscess & 15 & 14.2 \\
Non-specific Mastalgia- & & \\
Cyclical- Non-cyclical & 1204 & 11.33 .8 \\
Fibroadenoma & 10 & 9.4 \\
Disease of nipple & 10 & 9.4 \\
Carcinoma breast & 2 & 1.9 \\
Galactocele & 1 & 0.94 \\
Eczema & 1 & 0.94 \\
\hline Total & 106 & 100 \\
\hline
\end{tabular}

Table-II shows that out of 106 patients with breast pain majority (48.1\%) were due to ANDI. Among the other causes nonspecific pain (15.1\%), breast abscess (14.2\%), diseases of nipple (9.4\%), fibroadenoma (9.4\%) carcinoma of breast (1.9\%), galactocele $(0.94 \%)$ and eczema (0.94\%).

\section{Table-III}

Distribution of the performance status $(n=106)$ Diagnosis of patientsPerformance Status

\begin{tabular}{lcccccc}
\hline & 0 & 1 & 2 & 3 & 4 & 5 \\
\hline ANDI n= 51 & 40 & 11 & 0 & 0 & 0 & 0 \\
$\begin{array}{l}\text { Non-specific } \\
\text { mastalgia n=16 }\end{array}$ & 10 & 6 & 0 & 0 & 0 & 0 \\
$\begin{array}{l}\text { Breast abscess } \\
\mathrm{n}=15\end{array}$ & 7 & 8 & 0 & 0 & 0 & 0 \\
$\begin{array}{l}\text { Disease of nipple } \\
\mathrm{n}=10\end{array}$ & 8 & 2 & 0 & 0 & 0 & 0 \\
Carcinoma of breast & 1 & 1 & 0 & 0 & 0 & 0 \\
$\mathrm{n}=2$ & & & & & & \\
Galactocelen=1 & 0 & 1 & 0 & 0 & 0 & 0 \\
$\begin{array}{l}\text { Skin lesion(eczema) } \\
\mathrm{n}=1\end{array}$ & 1 & 0 & 0 & 0 & 0 & 0 \\
\hline
\end{tabular}

This table shows that, the performance status of all the patients were in between $0-1$. 
Table-IV

Distribution of the investigation yielding positive result

\begin{tabular}{|c|c|c|c|c|}
\hline Investigation & $\begin{array}{l}\text { No of patients } \\
\text { done with pain }\end{array}$ & $\begin{array}{l}\text { Positive result } \\
\text { No. (\%) }\end{array}$ & & Negative result \\
\hline \multirow[t]{3}{*}{ Mammography } & 54 & Fibrocystic disease: & $41(93.2)$ & Total : 10 \\
\hline & & Fibroadenoma: & $03(6.8)$ & \\
\hline & & Total: & $44(100)$ & \\
\hline \multirow[t]{6}{*}{ FNAC } & 50 & Fibroadenoma: & $22(61)$ & Total : 14 \\
\hline & & Fibrocystic change: & $08(22.2)$ & \\
\hline & & Chr. breast abscess: & $02(5.6)$ & \\
\hline & & Mitotic lesion: & $02(5.6)$ & \\
\hline & & Neurofibroma: & $02(5.6)$ & \\
\hline & & Total: & $36(100)$ & \\
\hline
\end{tabular}

Table-IV shows that, mammography of the breast done on 54 patients where 44 and 10 patients were found positive and negative respectively. Out of 44 positive cases of mammography, 41 patients $(93.2 \%)$ revealed fibrocystic disease, and three patients (6.8\%) had fibroadenoma.

FNAC was done in 50 patients presented with pain. Out of 50 patients, 36 were found positive and 14 were found negative. Among them 22 patients (61\%) diagnosed as fibroadenoma, 8 patients $(22.2 \%)$ as fibrocystic change, 2 patients (5.6\%) as chronic breast abscess, 2 patients (5.6\%) as mitotic lesion, 2 patients (5.6\%) diagnosed as neurofibroma.

\section{Table-V}

Age distribution of ANDI ( $n=51)$

\begin{tabular}{lcc}
\hline Age(years) & Numbers of patients & Percentage \\
\hline$<20$ & 7 & 13.7 \\
$21-30$ & 29 & 56.9 \\
$31-40$ & 12 & 23.5 \\
$41-50$ & 2 & 3.9 \\
$>50$ & 1 & 2.0 \\
\hline Total & 51 & 100 \\
\hline
\end{tabular}

The table shows maximum patients (56.9\%) had ANDI, which were later diagnosed as fibroadenosis, were in the age group of $21-30$ years. Only one patient out of 51 cases is of more than 50 years.

\section{Discussion:}

In this series a total of 106 patients with a complaint of breast pain were studied from August 2002 to
January 2004 at breast clinic of Bangladesh Medical College Hospital and at Surgical Department of $\mathrm{BMCH}$.

The majority of the patients (35.8\%) with breast pain belong to the age group of 21-30 years (Table-1). This general age distribution is in agreement with studies done by Ekland DA et al who found $74 \%$ of his patients were below 40 years and AMSM Sharfuzzamanl found $48 \%$ of his patients were in the age group between 21 30 years. ${ }^{4,5}$

In this series, $48.1 \%$ patients were diagnosed as Aberration of Normal Development and Involution (ANDI), $15.1 \%$ as non-specific mastalgia and $14.2 \%$ as breast abscess. The next group was diseases of nipple $9.4 \%$, carcinoma of breast $1.9 \%$, galactocele $0.94 \%$, and eczema $0.94 \%$ (Table-2). This is comparable with the study Shresta S, Sen T et al. ${ }^{6}$ They found that overall $36.8 \%$ presented with cyclical mastalgia and $43.1 \%$ with noncyclical mastalgia. This result is also comfortably comparable with other literatures. Funder Burk et al in a review of 2582 breast lesions in blacks found that maximum cases (30\%) were fibrocystic diseases, followed by fibroadenoma $27 \%$, carcinoma $23 \%$ and rest $20 \%{ }^{7}$ But the results are slightly different in the study conducted by Oluwol and Freeman et al who analyzed 282 breast lesions in Black patients and noted that fibroadenoma was the most common (34.75\%) and then carcinoma(29\%) followed by fibroadenosis(17\%). ${ }^{8}$

Most of the patients in this study, describe their pain as heavy, aching and tender, and these descriptors were given significantly higher ratings by women with 
cyclical pain. In women with non-cyclical mastalgia, the overall pain severity was related to the size of the painful area, and the affective components were more prominent than in women with cyclical mastalgia.

The performance status of the patients was evaluated by UICC grade. The maximum patients with pain were $0-1$, so the activity and general health of the patients in this study group was satisfactory.

Mammography of the breast done on 54 patients where 44 patients were being positive. Of them mammography of $41(93.2 \%)$ patients revealed fibrocystic disease, 3 patients $(6.8 \% 0$ with Fibroadenoma and no abnormality detected in 10 patients reflecting that fibroadenosis is common cause of mastalgia (80\%).Value of diagnostic mammography lies in the early detection of breast lesions. Mammography is capable of imaging the breasts of older women better than those of younger, because the latter are more glandular and thus more radio dense. For this reason mammography is only of limited value as an investigation of breast symptoms in women aged less than 40 years. The accuracy of investigation is observer dependent and has been reported to be between $60-98$ percent. ${ }^{9-13}$

FNAC was done in 50 patients presented with pain, among them 22 diagnosed as fibroadenoma, 8 as fibrocystic change, two as chronic breast abscess, two as mitotic lesion, two as neurofibromatosis. In the review article of Kocjan $\mathrm{G}$, the current practice and role of FNAC in the diagnosis and management of breast lesions was explored and confirmed. ${ }^{14}$ FNAC has an advantage of being an immediate and excellent method for on-site examination and one-stop diagnosis at breast out-patient clinics. Since the majority of the patients attending a breast clinic have benign disease, they benefit from rapid diagnosis and discharge from the clinic. ${ }^{14,15}$ But FNAC cannot bring out any conclusive inference. In an evaluation study done by Somani A et al, it was found that out of 34 FNAC, for 6 benign and equivocal cytological diagnoses, subsequent histology disclosed one case of pure ductal carcinoma in situ, two cases of mococoele-like lesions with ductal carcinoma in situ, one case of invasive and ductal carcinoma in situ with neuro-endocrine features and two cases of invasive ductal carcinoma. So, diagnostic difficulties in cytological interpretation of aspirates from breast carcinoma in young women may lead to unwanted delays, which occurred in six $(17.6 \%)$ of 34 women in that study. ${ }^{16}$
Majority of the ANDI cases (56.9\%) were between the age group of 21-30 years. This has got similarity with the fact that it is more frequent between the age of 20 to 40 years. ${ }^{10-12,17,18}$

\section{Conclusion:}

Mastalgia is a common and distressing problem among women in this country. Many of the patients are brought to the physicians either for the acute pain, uncontrollable discharge or for the fear of cancer. After the latter is ruled out many of the problems can be managed by minor surgical procedures or even by simple reassurance.

\section{References:}

1. Burkitt HG, Quick CRG, Gatt DT, eds. Essential Surgery: Problems, Diagnosis \& Management, $2^{\text {nd }}$ ed. London: Churchill Livingstone,1996: 523-545.

2. Cooper A. Illustrations of diseases of breast. London: S. McDowall, 1829.

3. Rahman SM. Mastalgia \& its clinico-pathological evaluation - a study of 50 cases (dissertation). Dhaka: Bangladesh College of Physicians \& Surgeons, 2000 [Unpublished dissertation].

4. Ekland DA, Zeigler MG. Abscess in non-lactating breast. Arch Surgery 1973;107:398-401.

5. Sharfuzzaman AMSM. Clinico-pathological study of breast abscess-Study of 50 cases (dissertation). Dhaka: Bangladesh College of Physicians \& Surgeons, 2000 [Unpublished dissertation].

6. Shrestha S, Sen T. Analysis of mastalgia cases presented at Manipal Teaching Hospital, Pokhara, Nepal. Nepal Med Coll J 2004;6:129-32.

7. Funderburk WW, Rosero E, Leffall CD. Breast lesions in Blacks. Surg. Gyenaecol. Obstet: 1972; 135: 58-60.

8. Oluwole SF, Freeman HP. Analysis of benign breast lesions in Blacks. Am. J Surg 1979; 137:786-789.

9. Doherty GM, Laurence W, eds. Current Surgical Diagnoses \& Treatment, $11^{\text {th }}$ ed. Connecticut: Prentice- Hall International Inc, 1994; 319-330.

10. Russel RCG, Williams WS, Bulstrode CJK, eds. Baily \& Love's, Short practice of Surgery, $24^{\text {th }}$ ed. London: Arnold, 2000: 824-40.

11. Sabiston DC. Biology Basis of Modern Surgical Practice. In: Text Book of Surgery, $15^{\text {th }}$ ed. Philadelphia: Saunders Company, 1997: 555-593. 
12. Cuschiaria A, Giles GR, Moosa AR, eds. Essential Surgical Practice, $3^{\text {rd }}$ ed. Oxford: ButterworthHeinemann Ltd, 1995:980-981.

13. Ikeda DM, Baker DR. Clinical indications and breast MRI- reporting system. J Magn Reson. Imaging 2000;12:975-983.

14. Kocjan G. Needle aspiration cytology of the breast: Current perspective on the role in diagnosis and management. Acta Med Croatica 2008; 62 : 391401.

15. Kocjan G, Bourgain C, Fassina a, et al. The role of breast FNAC in diagnosis and clinical management:
A survey of current practice. Cytopathology 2008; 19: 271-8.

16. Somani A, Hwang JS, Chaiwun B, et al. Fine needle aspiration cytology in young women with breast cancer: Diagnostic difficulties. Pathology 2008; 40: 359-64.

17. Cotran Kumar V, Robbins SL, eds. Robbins Pathologic Basis of Disease, $5^{\text {th }}$ ed. Philadelphia: WB Saunders Company, 1994;1089-1111.

18. Ray PS. Role of FNAC in diagnosis of breast lump study of 100 cases. Dhaka: Bangladesh College of Physicians \& Surgeons, 2000 [Unpublished dissertation]. 